\title{
Application of Mild and Alloy Steels to High-Tension Suspension Lines
}

\author{
BY L. R. O'NEILL \\ Cheif Engineer, Maryland Pressed Steel Co., Hagerstewn, Md.
}

\begin{abstract}
A discussion of the application of stamped and pressed steel units of mild, structural and alloy steel to the suspension problem in high-tension transmission.

Factors to be considered in the design of hardware for line construction.
\end{abstract}

\section{$\mathrm{T}$} HE tremendously rapid development of long distance transmission of electrical energy at high potential involves most interesting problems in line construction and in insulation. As the structural engineer has been called on to design steel towers to support 500 foot spans and the ceramic engineer to develop porcelain capable of insulation against potentials of 150,000 volts, so the mechanical engineer finds opportunity for the application of his knowledge and training in the development of metallic units involved in the suspension of the line itself. His problem is the development of a suitable means of connection between the tower, the porcelain insulator and the line. The result of his work must insure a mechanical strength as high as the porcelain, the weakest element in the chain, it must be capable of application to the porcelain with due consideration for the wide range of temperature coefficients, and it must finally be capable of adequate protection against atmospheric and gaseous corrosion. Although the hardware element of the line is at first thought a problem of minor importance, it should be given just as careful study as any other element of the line in order to offer the highest possible degree of insurance against interrupted service.

Briefly stated, the hardware problem involves the production of units having a yield point as high as the highest strength of porcelain insulators, the lightest possible weight to insure that strength, a means of application which will offset, as far as may be, the variation in volumetric expansion due to extremes of temperature and finally a construction which will permit the most complete protective measures possible. Although the initial cost of installation generally is a factor of relatively minor importance and subservient to the consideration of longevity and efficiency, that cost is still worth serious consideration as the dollar value changes and all costs advance to hitherto unheard of altitudes.

A study of existing high-tension lines and their history shows that practically nothing has been seriously considered in the design of line hardware other than malleable and grey iron castings and drop forgings of mild steel. The reasons are quite obvious. High tension designing is relatively a new art. The large number of engineers engaged in its pursuit have an

To be presented at the Pacific Coast Convention, A. I. E. E., Portland, Ore., July 21-23, 1920. almost equally wide range of ideas of design; the rapid development of the art itself has made necessary frequent changes of design. Both castings and forgings are comparatively easy to change, the change involving, as a rule, no great cost. Until 1916 malleable iron castings were relatively inexpensive and the original pattern cost is so small as to add but slightly to the cost of the finished unit. As in many other lines of industry, we find a decided lack of familiarity with the possibilities of working sheet steel into such shapes as come within the field. As an example of this particular point it is only within the last year or so that the manufacture of heavy truck brake drums has been accomplished except by casting them of steel. They are now made by drawing a drum of suitable size and weight from a flat sheet. Such a drum is stronger, more nearly perfect as to shape and requires less machining. Examples such as this might be taken from a dozen different fields. We have all been perhaps somewhat slow to consider or to adopt pressed steel designs, electrical engineers because they did not know just what could be done in that field, the pressed steel engineer himself because it is only within the past few years that he has been able to do it. Beside other limitations it has been difficult for him to obtain from the steel mills a raw material of sufficient homogeneity and uniformity of chemical composition. to permit practical manufacturing operations. Similarly it is only within the last few years that the makers of cutting steel have developed a product suitable for long continued operations of such intricacy and severity as is required.

These conditions are now overcome. We can run 100,000 units through production involving severe drawing and forming operations and have a total loss of less than 1 per cent due either to material or workmanship. Our cutting steels are reliable and relatively inexpensive, the development of the art of high-tension transmission is itself sufficiently settled to permit quantity production, and finally the cost of forgings and castings, because both involve the use of skilled labor, has risen out of all proportion. The field is now open to stampings and it seems proper that we should consider what can be done and how it can be applied to the problem in hand.

In reply to that question, the presse dsteel manufacturers say that practically anything can be made in pressed steel, provided the quantity warrants the ef- 
fort. The various insulator manufacturers have each their own ideas as to the proper way to apply a porcelain insulator to the line. We have heard the claims made by those who believe in the cap and pin type and in warm opposition thereto the claims of those manufacturers who believe only in the spider type. One engineer asserts that a line clamp should not clamp the line at all but merely support it. The next engineer asserts quite as positively that a line clamp should be capable of resisting at least a 600-pound pull in tension. We are told that a strain clamp should be used by separating the steel core from the body of the cable and we are also told that this should never be done. It is not at all the province of the pressed steel engineer to discuss these points; they belong distinctly to the electrical engineer. It is our function to meet each one on his own ground and out of our own knowledge and experience in working steel offer him a construction and design which will meet his particular requirements. It is as easy or as difficult for us to make a suitable cap as it is to make a suitable spider. We can make a strain yoke out of a single piece of merchant bar $1 / 4$ in. by $21 / 2$ in. or out.of a flat sheet $1 / 8$ in. thick and perhaps $16 \mathrm{in}$. square. If our client today requires a line clamp which will solidly clamp the cable with a clip or a bridge plate we can do it. If tomorrow he prefers a clamp which will exert less pressure, that is equally easy or equally difficult. If you will consider the variety of odd shapes and strange sizes now being made in heavy presses you will be amazed. Axle housings, engine oil pans, railway ties, car seat pedestals, wire wheel hubs, clutch housings, interior wiring devices such as junction boxes, switch housings and bosses, all these are live testimony to the possibilities of the trade. Whether the design required metal in thousandths of an inch or quarter of an inch one has but to design suitable tools and feed the steel into a press. If cross-sections of varying thickness are required, they can be obtained by folding the metal on itself or by varying the thickness in the course of the drawing operation. If the desired shape cannot readily be formed from a single sheet, welding, either electric or touch is available and a perfectly reliable unit results. The uniformity of the product greatly reduces and usually eliminates machining and grinding operations; the unit is ready for use when it comes from the press. Of course such designs require careful study and a considerable knowledge not only of the art of working sheet steel but involve at least some degree of familiarity with problems of the electrical engineer.

Having in mind that we are presenting something relatively new, we ask that you consider what advantages pressed steel offers over malleable castings and forgings. Pressed steel units are uniform. You may pick up half a dozen units from a pile and caliper them, not with a scale but with a micrometer, and you will find variations which are to be measured in only a few thousandths of an inch. Holds line up perfectly. Caps are of absolutely uniform inside and outside diameters within a few thousandths of an inch. There is a corresponding uniformity of thickness and weight as well as finish. Uniformity such as this makes for easy handling and less expensive assembly with a complete absence of rectifying operations and fittings. Neither malleable, castings nor forgings are capable of such uniformity. The very nature of a casting involves considerable variation as to size and weight and one has only to go into an insulating plant to see castings being straightened with a hammer and filed or ground before they can be used. There is always a great variation in forgings and the flash or fins left by the dies is a variable factor, frequently involving more or less work before the unit can be used.

The physical strength of the unit is assured. The malleable iron casting is made by pouring molten iron into a mould, cooling and annealing in a furnace. You insulator manufacturers know how difficult it is to keep a furnace temperature absolutely uniform and to be sure that every cubic foot of the interior of the furnace is at the same temperature as every other cubic foot. If these conditions are not at least approximated in annealing castings, there is a wide range of temper and consequently of strength. Forgings are subject to similar possibilities of defect. If steel is handled under a drop hammer at too low a temperature, crystallization begins and the unit lacks the strength it should have. All pressed steel units are free from such defects and require only the most casual inspection and test. The steel itself is made in either an open hearth furnace, a Bessemer converter, a crucible or possibly an electric furnace. It is poured into ingots and from each heat a sample is taken which is submitted to physical and chemical analyses to insure that the ingot itself is of the desired quality. The ingot is rolled into the desired shape and inherent defects in the steel show almost automatically in the process of rolling. When the steel reaches our hands its percentage of imperfection is very low indeed. In the course of making a particular unit the steel sheet is blanked, drawn, formed and stamped, each of these operations requiring the application of such loads as invariably bring out any imperfections which still remain. In the making of a spider for example, the blank is cut out of the steel with its six or eight legs in a plane. Some 280 tons are required to effect this blanking and under such pressure any defects in the steel become immediately visible. Following the blanking, the spider is formed up into its cup shape by pushing it through a cylindrical die, involving a pressure of perhaps 175 tons. The steel is here given a relatively sharp right angle bend and if there be a pipe or seam in the sheet it is shown at once. In like manner the various severe operations which are performed cold on sheet steel to effect the desired results are such as to bring out any imperfections which the 
steel may have. If malleable iron castings are to be used they must be designed with a very high safety factor and even then the production manager will have his troubles. The percentage of rejections on malleable iron castings are very much higher than in any pressed steel construction and in order to find out these rejections more or less elaborate testing facilities must be used on every piece. We do not need such tests with steel units. Forgings are less open to the criticism here applied and may properly be considered quite as satisfactory as pressed steel units in this connection.

The problem of protection against the corrosive action of the atmosphere and such influences as exhaust gases from locomotives and other sources has been given increasingly greater consideration during the past two or three years. Pressed steel units lend themselves better than any others to adequate protection by galvanizing, lead coating or enameling. They are clean and clear cut. Malleable castings show a certain inevitable percentage of units in which minute particles of slag and other impurities are imprisoned in the surface. Zinc applied by either the galvanizing or sherrardizing process to the castings cannot completely cover these tiny particles, an oasis is formed and in due time the salt air works its way along this little pinnacle of slag and underneath the zinc coating and our old enemy rust commences its work. Steel has no such surface imperfections and its protective coating is complete and impenetrable.

There is an unlimited supply of raw material of wide range. Units such as we are interested in can be made of anything from tank steel having an ultimate tensile strength of from forty to fifty thousand pounds to the square inch through the various grades of mild and structural steel having an ultimate tensile strength of approximately 75,000 pounds to the square inch up to alloy steels which include Chromium, Molybdenum and nickel which, with suitable heat treatment, will achieve an ultimate tensile strength of 180,000 pounds to the square inch: Malleable iron castings are limited to a narrow range of strength which may not extend beyond 44 or 45,000 pounds to the square inch. The relation of the yielding point to the ultimate tensile strength in steel may be quite definitely controlled within a considerable range and in the case of alloy steels, by proper heat treatment, may be brought up to 80 per cent of the ultimate strength insuring the highest possible usable strength with the least possible weight. Such a range of material from which to choose for our production certainly demands serious consideration.

The readiness with which the raw material itself can be secured is also a considerable factor. Go, if you will, to a malleable foundry and ask for 500 tons of malleable castings and at the same time ask a steel mill for 500 tons of sheet and learn for yourself at first hand which is the easier to obtain.
Both malleable iron castings and drop forgings involve of necessity the use of skilled labor. The enormous increase in the use of malleable castings and drop forgings in the automobile industry has resulted in demands on the foundries and forges which they cannot possibly fill, partly because of lack of equipment and partly because of the shortage of skilled labor. One cannot make a moulder or a hammerman overnight. If pressed steel constructions are used the employment of a relatively small number of very highly skilled mechanics is necessary only for the making of tools. The actual production of the unit itself is in the hands of unskilled labor which not only works at a relatively low wage but can be trained in two or three days to a high degree of efficiency. As in the production of the steel itself the machine does the work.

Quick deliveries are possible in steel. The ready availability of raw material and the relatively short time required to make tools insures an early start on the work. Most of the units which are likely to be used in this field can be turned out at the rate of at least from three to four hundred per hour and can be finished within the time required to put them through the various operations. Malleable iron castings must be annealed and the annealing process takes from three to seven weeks. The first piece must perforce wait on the necessary pattern equipment. Drop forgings cannot be handled so rapidly. The tools take practically as long to make as tools for sheet steel construction and it is never quite so easy to get exactly the right sizes of steel required to make a forging as it is to cut up a sheet of steel to the dimensions suitable for blanking. When a contract is finally let for the construction of a line, someone invariably wants hardware about two or three days later. It is certainly worth while to know that pressed steel units can be turned out in quantities in generally less time than any other construction.

Finally, we have to consider the question of cost. One is no longer shocked at being asked to pay from 12 to 18 cents per pound for malleable iron castings and prices as high as 24 cents per pound are not exactly new. The initial cost is not the only cost because extra fitting and inspections are required. Drop forgings at 12 cents per pound and higher are not uncommon. In contrast with these prices the raw material used for pressed steel units costs from 7 to 12 cents per pound for the steel best suited to this work, although alloy steels which are eminently desirable for certain conditions of extreme load may cost as much as 80 cents per pound. Very little calculation is required to show that the net cost is somewhat lower when operations which rarely number more than ten are performed at a rate of from three to five hundred per hour. The cost of tools which must naturally be amortized over the entire production is a factor of considerable importance. Generally speaking, the larger the unit by weight the lower the price because the labor 
element of the cost remains practically the same, and it is probably safe to say that when pressed steel designs can be offered in lieu of castings or forgings the price will be somewhat lower and as a result of our experience there seems little reason to doubt that their efficiency is considerably higher.
In conclusion the engineers who represent the various pressed steel manufacturers are ready and willing to handle such problems as you may offer them, to apply the fruit of their experience in other lines and to work in close cooperation with you in the development of the high-tension lines.

\title{
Bridge Methods for Alternating-Current Measurements
}

\author{
BY D. I. CONE \\ Pacific Telephone \& Telegraph Company, San Francisco, Cal.
}

$\mathrm{T}$ HE extension of the field of application of electric energy to human service requires'more and more of measurements of electrical quantities, of varying grades of precision. Very prominent in the history of electrical measurements is the so-called "bridge" method, the fundamental principle of which is the equalizing of the potentials of two chosen points in a network of electric circuits. The original application of this principle was made by S. H. Christie in 1833 to the measurement of resistance to direct current in the arrangement long familiarly known as the Wheatstone Bridge. Numerous forms of Wheatstone Bridge for direct-current measurement have been developed. The conditions for its use have been investigated thoroughly and are well-known.

Of later development and less known and understood are the applications of the bridge principle to measuring impedances of alternating-current circuits. However, the knowledge of the Wheatstone Bridge as used with direct current can immediately be made use of for alternating-current testing by applying the principle stated by Kennelly in the following words. ${ }^{1}$

It is however, a seemingly universal and a wonderful law, that all the numerical formulas and rules of quantitative behavior for continuous-current circuits, or conductors, are exactly the same for single-frequency alternating-current circuits or conductors, in respect to potentials and currents as also (with minor reservations) to power and energy if these formulas and rules are interpreted as relating to complex numbers.

The purpose of this paper is to present a resumé of simple methods of utilizing "bridge" networks in alternating-current measurements of impedances and their components of effective resistance, self and mutual inductance and capacitance, and in frequency measurement.

A great variety of arrangements have been described by numerous writers. It is not attempted to include all of these, but to present such a group as will give latitude of choice to suit the apparatus that is available, or permit the use of several methods to check against each other. By the methods shown approximate measurements over wide ranges of values can

To be presented at the Pacific Coast Converition, A. I. E. E. Portland, Ore., July 21-23, 1920.

1. Kennelly-Hyperbolic Functions Applied to Electrical Engineering. be made with very simple apparatus. It is hoped that others will add from their experience to the value of the collection.

Before taking up the various practical forms of bridge network, it will be helpful to consider the conditions for balance and other characteristics of a "Wheatstone bridge" wherein the four resistances are replaced by impedances. Thus generalizing the Wheatstone bridge network and utilizing the ordinary formulas in accordance with the principle quoted from Kennelly's statement given above, the relations shown

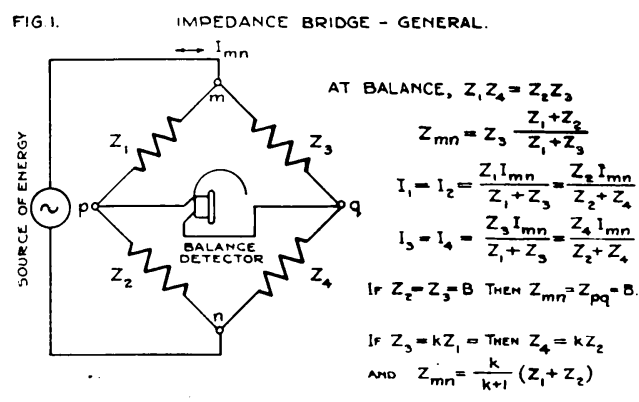

FIG. 1

in Fig. 1 are determined. In place of resistance is written the impedance.

$$
\text { Where } \begin{aligned}
Z= & \sqrt{R^{2}+X^{2}} / \theta=R+j X \\
X & =\text { effective resistance } \\
X & \quad \text { effective reactance } \quad+\text { capacitive) } \\
\theta= & \tan ^{-1} \frac{X}{R}
\end{aligned}
$$

The standard rules for combining complex numbers must of course be observed in using the formulas. Besides the formula connecting the several impedances at balance, the impedance of the whole bridge between the corners $m$ and $n$ is given, also the division of current among the branches. These are useful when it is necessary to determine the current input to the circuit whose impedance is being measured. It is of interest that when two opposite impedances of the network, as $Z_{2}$ and $Z_{2}$ or $Z_{1}$ and $Z_{4}$, are equal, the impedances $Z_{m n}$ and $Z_{p q}$ are alike equal to that same value.

Interchanging the energy source and balance detector connections, (energizing at $p, q$, and equating the 